\author{
Cadernos de \\ ESTUDOS LINGUIISTICOS - (59.1), Campinas, pp. 197-214 - jan./abr. 2017
}

\title{
A CONSTRUÇÃO DOS CONTEXTOS DE REFERÊNCIA EM NARRATIVAS AMAZÔNICAS: UM ESTUDO DA ANÁFORA INDIRETA
}

\author{
HELIUD LUIS MAIA MOURA*
}

\begin{abstract}
RESUMO: Este artigo tem por objetivo analisar anáforas indiretas constitutivas de narrativas amazônicas, observando-se a forma como essas anáforas constroem processos referenciais engatilhados no contexto sociodiscursivo no qual essas histórias são produzidas. O referencial teórico tem como base as postulações de Koch (2004, 2006, 2008); Marcuschi (2005, 2006, 2007); Schwartz (2000); Tesnière (1977); Fillmore (1997) e Moura (2013). Para os autores, a construção de anáforas indiretas constitui uma atividade sociocognitiva e cultural, para a qual são mobilizados diversos processos, precisamente no que concerne a tipos de relações semânticas, a papeis temáticos de verbos, a nominalizações, esquemas cognitivos e modelos mentais, procedimentos inferenciais, em que estão em jogo não só elementos estritamente textuais, mas, sobretudo, elementos engatilhados em contextos de referência nos quais as ações de linguagem são produzidas. O corpus, em análise, consta de 17 (dezessete) narrativas, as quais fazem parte de 13 (treze) números da Revista Visagens, Assombrações e Encantamentos da Amazônia, de autoria do escritor paraense Walcyr Monteiro. Esses números foram publicados entre os anos de 1997 e 2004 e tematizam sobre os personagens: Boto, Cobra, Matintaperera e Curupira, assim como acerca de assombrações e visagens. As análises realizadas levam-me a concluir que os processos anafóricos indiretos são constitutivos das narrativas em estudo, assim como reafirmam o fato de que estes reconstroem significados simbólicos, sociocognitivos e discursivos veiculados no processo de produção das narrativas sob investigação.
\end{abstract}

Palavras-chave: Linguística textual; referenciação; anáfora indireta.

ABSTRACT: This article aims to analyze indirect anaphora constitutive of amazonian narratives, observing the way in which these anaphora constructs referential processes set in the socio-discursive context in which these stories are produced. The theoretical framework is based on the postulates of Koch's (2004, 2006, 2008); Marcuschi (2005, 2006, 2007); Schwartz (2000); Tesnière (1977); Fillmore (1997) and Moura (2013). For the authors, the construction of indirect anaphora is a sociocognitive and cultural activity, for which various processes are mobilized, precisely as regards types of semantic relations, thematic roles of verbs, nominalizations, cognitive schemas and mental models, procedures inferential, in which not only strictly textual elements are at stake but, above all, elements set in reference contexts in which language actions are produced. The corpus, in analysis, consists of 17 (seventeen) narratives, which are part of 13 (thirteen) numbers of Magazine Visagens, Assombrações e Encantamentos da Amazônia, by the author of the Paraense Walcyr Monteiro. These numbers were published between the years of 1997 and 2004 and theme about the characters: Boto, Cobra, Matintaperera and Curupira, as well as about hauntings and visions. The analyzes carried out lead me to conclude that indirect anaphoric processes are constitutive of the narratives under study,

*Universidade Federal do Oeste do Pará, Pará (PA), Brasil. heliudlmm@yahoo.com.br 
as well as reaffirming the fact that they reconstruct symbolic, sociocognitive and discursive meanings conveyed in the process of producing the narratives under investigation.

Keywords: Textual linguistics; referral; indirect anaphora.

\section{INTRODUÇÃO}

Meu objetivo, neste artigo ${ }^{1}$, é analisar anáforas indiretas constituintes de narrativas amazônicas, observando a forma como essas anáforas constroem processos referenciais ancorados no contexto no qual são produzidas. Tomo como referencial teórico as postulações de Koch (2004, 2006, 2008); Marcuschi (2005, 2006, 2007); Schwartz (2000); Tesnière (1977); Fillmore (1997) e Moura (2013). Para esses teóricos e autores, a referenciação, no âmbito das anáforas indiretas, constitui uma atividade sociocognitiva e cognitivo-cultural, para a qual concorrem diferenciados processos, especificamente no que diz respeito a tipos de relações semânticas, a papeis temáticos de verbos, a nominalizações, esquemas cognitivos, modelos mentais e procedimentos inferenciais em que estão em jogo fatores não só propriamente textuais, mas, sobretudo, fatores engatilhados em contextos de referência nos quais as ações de linguagem são produzidas e fazem sentido.

O corpus, a partir do qual fiz o recorte para este artigo, consta de 13 (treze) números da Revista Visagens, Assombrações e Encantamentos da Amazônia, cujo autor é o escritor paraense Walcyr Monteiro. Esses números foram escritos entre os anos de 1997 e 2004 e tematizam sobre histórias de Boto, Cobra, Matintaperera e Curupira, assim como acerca de assombrações e visagens. Os citados números foram publicados pela Editora Smith - Produções Gráficas, na cidade de BelémPA. As histórias constantes, nessa revista, são (re)criações do mencionado autor e estão ancoradas no universo sociodiscursivo e cultural amazônico.

Vale ressaltar que as anáforas indiretas, presentes nessas narrativas, reconstroem, por diferentes formas ou processos, significados socioculturais em veiculação no seu contexto de produção, a partir do qual o produtor textual constrói as histórias sob análise.

\section{BASES TEÓRICAS}

Considerando o modo como os processos referenciais atuam na reconstrução da realidade biossocial e cultural, vejamos como Koch (2004) se posiciona em relação ao fenômeno da referenciação:

A referenciação constitui, assim, uma atividade discursiva. O sujeito, por ocasião da interação verbal, opera sobre o material lingüístico que tem à sua disposição, operando escolhas

${ }^{1}$ Este artigo é parte da minha tese de doutorado, defendida, em 2013, no Programa de PósGraduação em Linguística do Instituto de Estudos da Linguagem da Universidade Estadual de Campinas (UNICAMP), sob a orientação da Prof ${ }^{a}$. Dr ${ }^{\mathrm{a}}$. Anna Christina Bentes da Silva. 
significativas para representar estados de coisas, com vistas à concretização de sua proposta de sentido (Koch, 1999, 2002). Isto é, os processos de referenciação são escolhas do sujeito em função de um querer-dizer. Os objetos-de-discurso não se confundem com a realidade extralingüística, mas (re)constroem-na no próprio processo de interação. Ou seja: a realidade é construída, mantida e alterada não somente pela forma como nomeamos o mundo, mas, acima de tudo, pela forma como, sociocognitivamente, interagimos com ele: interpretamos e construímos nossos mundos por meio da interação com o entorno físico, social e cultural.

Assim sendo, defendemos a tese de que o discurso constrói aquilo a que faz remissão, ao mesmo tempo que é tributário dessa construção. Como dissemos, todo discurso constrói uma representação que opera como uma memória compartilhada (memória discursiva, modelo textual), "publicamente" alimentada pelo próprio discurso (Apothéloz \& Reichler-Béguelin, 1999), sendo os sucessivos estágios dessa representação responsáveis, ao menos em parte, pelas seleções feitas pelos interlocutores, particularmente em se tratando de expressões referenciais. (KOCH, 2004, p. 61).

Conforme expresso pela citação da autora, posso afirmar que a referenciação constitui um conjunto de estratégias por meio das quais o sujeito dá sentido ao mundo biossocial, não só reconstruindo-o por meio de suas interações, mas imprimindo novas significações a significados sociais (linguisticamente revestidos) já estabelecidos.

Indo um pouco mais além no âmbito das concepções teóricas acerca dos processos referenciais, observemos o que afirma Marcuschi:

Defendo a tese geral de que não são os fatos que produzem as significações presentes em nossas compreensões e sim as nossas compreensões que fundam e constroem as significações que atribuímos aos fatos. Na realidade, isso significa que não há um a priori nem um centro regulador da significação, mas ela é produto de interações sociais no interior da cultura e da história. Daí ser o próprio conhecimento um projeto cultural e não um dado natural ou um fruto de relações de correspondência sujeito-objeto. O melhor é pensar em termos de sujeitoobjeto-sujeito: duas subjetividades criando uma realidade intercomunicável. Sentidos são bens humanos e não fenômenos naturais. (MARCUSCHI, 2007, p. 80).

Alicerçando-me nas postulações de Marcuschi e de outros teóricos aqui apresentados, proponho que os significados sociais e culturais embutidos nos artefatos simbólicos, como narrativas e contos populares, expressam estratégias referenciais coadunadas com práticas linguísticas situadas, que, por seu turno, manifestam valores particulares de certas comunidades. Logo, aspectos da cognição cultural podem influir no processo de produção desses artefatos, viabilizando estratégias sociocognitivas associadas a procedimentos linguísticodiscursivos específicos, importantes para a execução dos objetivos interacionais desses grupos culturais.

Mediante o exposto, é preciso dizer que as atividades de construção da referência, entendidas aqui como um conjunto de processos complexos e multivariados, implicam a existência de indefinidas formas de gerenciamento do sentido quando da reconstituição de outros sentidos, sendo estes reatualizados pelo "movimento"2 dinâmico das interações sociais e culturais, apresentando-se

${ }^{2}$ A palavra movimento, aí aspeada, indica que as interações sociais são caracterizadas pela instabilidade dos próprios contextos em que se inserem. 
tais atividades sempre emergenciadas e imprevisibilizadas pelos contextos nos quais atuam e como consequentes destes, com um maior ou menor controle e "descontrole" desses sentidos no transcurso da produção das atividades textuais.

Assim, entendendo as atividades textuais como processos essencialmente culturais e, portanto, como contentoras de expressões que veiculam sentidos referenciais ligados a práticas definidas por determinados contextos, Moura (2013) defende que a interpretação das formas de referência não pode ser isolada dos sentidos produzidos por tais contextos. Nessa perspectiva, advoga que, de maneira mais direta, ou mesmo por meio de elementos indiciadores, o conteúdo de tais expressões reconstitui/recoloca simbolicamente sentidos instalados nas práticas dos diversos lugares sociais. Mais ainda: como as expressões referenciais não estão dadas ou prontas pelo sistema linguístico em si mesmo, mas são, segundo Marcuschi (2007), construídas pelos sentidos trabalhados nas interações, elas são, pois, passíveis de aquisição contínua de novos estatutos linguístico-discursivos, com obtenção de outras propriedades e funções, por meio das quais servem aos objetivos pretendidos pelos interactantes no carreamento da atividade verbal.

Koch (2004) trata da existência de formas de introdução (ativação) de referentes no modelo textual. Para ela, são dois tipos de processos envolvidos nessa introdução/ativação:

(i) a introdução não-ancorada - aquela em que um objeto-de-discurso totalmente novo é inserido no texto, passando a localizar-se no "endereço cognitivo"4 contido na memória do interlocutor. Ao ser representado por uma expressão nominal, esse tipo de introdução implementa uma categorização do referente; (ii) a "ativação" ancorada - quando um novo objeto-de-discurso é introduzido, sob forma de algo dado, em razão de algum tipo de conexão com elementos situados no cotexto ou no contexto sociocognitivo, podendo ser estabelecida por mecanismos associativos e/ou inferenciais. Figuram entre esses casos as anáforas associativas e as anáforas indiretas.

Os tipos de processos, acima colocados, podem ser compreendidos também como macroestruturas sociocognitivas por meio das quais podemos entender subestruturas mobilizadas ou atuantes nas atividades referenciais, com diferenciações resultantes do estatuto semântico-discursivo específico a formas ou expressões pertencentes a essas subestruturas.

Assim, no âmbito dessas subestruturas ou subprocessos, estão as anáforas associativas e as anáforas indiretas. As primeiras, conforme Koch (2008), consistem de configurações discursivas em que se tem um elemento anafórico sem antecedente literal explícito e, portanto, não atrelado morfossintaticamente

\footnotetext{
${ }^{3}$ A expressão “descontrole”, que está aí entre aspas, indica que, nos processos de referenciação, o gerenciamento dos sentidos nem sempre se dá de forma previsível e predefinida.

${ }^{4}$ Aspas da autora.

${ }^{5}$ Aspas da autora.
} 
a um SN precedente, mas cuja ocorrência implica um detonatum implícito, que é reconstruído por um mecanismo de inferência a partir do cotexto anterior. Já as segundas, de acordo com Marcuschi (2005) e Schwarz (2000), referem-se a expressões definidas, como também a expressões indefinidas e pronominais, que se acham na dependência de interpretação em relação a determinadas expressões ou informações constantes da estrutura textual anterior ou posterior e que possuem duas funções referenciais textuais: a inserção de novos referentes - até então não nomeados diretamente - e a continuidade da relação referencial mais global.

No caso da anáfora indireta, tomando como fundamento as postulações de Schwarz (2000), pode ser encarada como um recurso referencial-discursivo em que a ancoragem anafórica não se dá pari passu na estrutura textual, mas por meio de relações ou inter-relações de sentidos mais amplas, nas quais os referentes são reconstruídos ou ativados por meio de estratégias inferenciais, oportunizando a viabilização de conhecimentos sociais e culturais compartilhados e que estão presentes na memória dos interactantes.

Assim, aponto aqui algumas considerações feitas por Koch (2006), baseadas nas proposições de Schwarz (2000), nas quais esta primeira autora afirma que

as anáforas indiretas têm recebido na literatura diversas denominações: inferenciais, mediatas, profundas, semânticas, associativas. Adoto aqui a denominação de anáforas indiretas, seguindo a argumentação de Schwarz (2000), de que existem diferentes tipos dessas anáforas, que podem ser classificadas com base nas operações cognitivas e representações de conhecimentos necessárias à sua interpretação. Segundo a autora, muitas anáforas indiretas não são explicáveis por simples relações de associação (termo que, inclusive, ainda careceria de melhor esclarecimento), mas sim por complexos processos conclusivos, que não se resumem à relação associativa. Defende a posição de que nem toda anáfora indireta depende de processos inferenciais, já que estes, para ela, se resumiriam àqueles processos cognitivos que ativam informações representadas na memória enciclopédica dos interlocutores. Tais inferências seriam de dois tipos:

1. ativação de conhecimentos de mundo armazenados na memória de longo termo para a desambiguização, precisão ou complementação de unidades e estruturas textuais;

2. a construção de informações, ou seja, a formação dinâmica e dependente de contexto ("situada") de representações mentais, com vistas à construção do modelo de mundo textual. (KOCH, 2006, p. 108).

O que podemos acrescentar às afirmações de Koch é que as anáforas indiretas constituem formas de ativação de referentes nas quais não há um elemento diretamente recuperável pelo cotexto, mas cuja recuperação é dependente da ativação de processos cognitivos ligados a fatores contextuais, pragmáticos ou situacionais e a conhecimentos de mundo comuns aos participantes da interação. Logo, nesse jogo interativo, as (in)definições acerca da alocação do sentido ativado por certos referentes podem ser resolvidas pela memória sociocultural e enciclopédica partilhada, o que nem sempre traduz-se em clareza e pontualidade semântica ou interpretativa no que tange aos sentidos veiculados na relação estabelecida entre um item e o outro elemento do qual deduz-se haver um nexo de implicação referencial.

Ainda segundo Koch (2006), baseada nas concepções de Schwarz (2000), o quadro das anáforas indiretas é bem complexo, pois não somente se podem observar vários tipos, mas também tipos híbridos e situações limítrofes ou pouco 
definíveis. Em alguns casos, a ancoragem pode ocorrer por meio de representações linguísticas de complexidade sintática, semântica e conceitual bastante variável.

Para a autora em questão, a interpretação das anáforas indiretas, baseia-se em conhecimento semântico de formas verbais e/ou nominais, e/ou em conhecimento do tipo conceitual, e/ou em conhecimento do tipo inferencial. Com base nisso, a citada autora faz a seguinte classificação das anáforas indiretas:

(i) de tipo semântico - baseadas no léxico;

(ii) de tipo conceitual - baseadas em conhecimentos de mundo (esquemas ou frames);

(iii) de tipo inferencial - tendo por base inferências.

De acordo com Koch (op. cit.), entre os tipos semânticos e os inferenciais existem aqueles que integram estágios intermediários e que podem ser organizados gradualmente em uma escala referencial-textual indireta.

Em função das considerações acima realizadas, coloco como válidas e procedentes as seguintes conclusões acerca do estatuto discursivo-referencial das anáforas indiretas:

(i) os tipos de anáforas indiretas são atrelados a domínios textuais de referência, tanto diretamente no cotexto como por indiciamento realizado por meio de formas nominais e/ou verbais;

(ii) os mencionados domínios de referência engatilham estruturas textuais a elementos contextuais de natureza situada, a partir do que é possível compreender certos tipos de ancoragem;

(iii) as anáforas indiretas, em sua maioria, apresentam relações do tipo parte-todo, as quais integram campos ou domínios semânticos conjugados, passíveis de serem recuperados por estratégias de contextualização e inferenciação;

(iv) as anáforas indiretas constituem recursos estruturantes da cadeia referencial inerente a um dado texto, de modo a caracterizar o tipo de atividade sociodiscursiva e sociointerativa posto em execução dentro de um quadro ou universo contextual de referência.

Diante do que aqui foi apresentado acerca das anáforas indiretas, podemos propor que estas integram um macroprocedimento de construção das ações referenciais exigidas pelas produções textuais, nas quais as ancoragens indiretas ou não-correferentes colocam-se como constituintes da própria natureza das atividades verbais e não como exceções destas, o que referenda a premissa de que a língua e a linguagem são lacunares e contingenciadas pelos contextos em que estão imersas.

\section{ANÁLISE DAS ANÁFORAS INDIRETAS}

A composição do corpus sob investigação apontou a presença de uma quantidade significativa de anáforas indiretas, ligadas tanto aos processos de 
construção de personagens afiliados ao universo lendário como a eventos e situações associados a esses personagens ou entidades. Assim, posso afirmar que esses recursos textuais entram no modo de constituição das narrativas em estudo, tendo em conta as atividades referenciadoras aí embutidas.

Portanto, considerando os personagens citados e os eventos ligados a estes, as anáforas indiretas atuam como elementos que asseguram a manutenção do sentido veiculado por determinadas expressões da estrutura textual precedente ou subsequente. Tal sentido está vinculado a ou ancorado em objetos-de-discurso elaborados em função de entidades como Boto, Cobra, Matintaperera e Curupira, com funcionamento específico dentro dos textos analisados e estando conectados, de forma direta ou indireta, às escolhas feitas pelo produtor das histórias e a fatores sociodiscursivos de seu contexto de produção. As anáforas indiretas analisadas, nesta categoria, têm como algumas de suas características mais prototípicas:

- a inserção de novos referentes ligados a fenômenos e estratégias de recategorização de elementos já introduzidos anteriormente no texto.

- os sentidos carreados por essas anáforas estão relacionados à natureza dos personagens e eventos característicos das histórias em investigação.

- as anáforas indiretas constituem recursos imprescindíveis e necessários à progressão referencial, com a desativação de um objeto-de-discurso e ativação de um novo, que passa a ocupar a posição focal.

- as anáforas indiretas constituem uma estratégia recorrente nos textos das narrativas em estudo.

Com base na tipologia desenvolvida por Schwarz (2000) e modificada parcialmente por Marcuschi (2005), procedo aqui, de acordo com a proposta de Marcuschi (2006), à interpretação de anáforas indiretas presentes no corpus. Tomo então, por base, a seguinte classificação:

1. AI baseadas em relações semânticas inscritas nos SNs definidos e indefinidos;

2. AI baseadas em papeis temáticos dos verbos;

3. AI baseadas em elementos textuais ativados por nominalizações;

4. AI baseadas em esquemas cognitivos e modelos mentais;

5. AI baseadas em inferências ancoradas no modelo do mundo textual;

6. AI sem antecedente cotextual.

Os 06 (seis) tipos acima colocados incluem, por vezes, subtipos; daí alguns conterem mais de um exemplo. O que vem a referendar variações mais específicas no que se refere à classificação aqui proposta, mas que não são objeto das análises implementadas neste trabalho.

Vejam-se, a seguir, os excertos em exemplo e as análises da AI aí contidas:

1 .

[...] Um dia, acompanhado de amigos, pegou o barco e foi a uma festa. Benevenuto ia falando que não acreditava nas histórias que contavam. E falou de novo: 
- Eu até queria ver uma encantada destas... Mas que fosse muito bonita...

Foram pra festa e dançaram, dançaram, dançaram... Quando terminou, Benevenuto separou-se dos demais e dirigiu-se para o barco sozinho. Ao se aproximar, viu aquela linda mulher, loura e muito bem feita de corpo, que se insinuou. Benevenuto era mulherengo, mas desta vez ficou receoso. [...]. (MONTEIRO, 2000, p. 19-20).

2.

[...] E o velho João começou sua narrativa.

- Olhe moço, já fazem uns tantos anos... Foi logo que me casei com $a$ Mundica. Ela era uma cabocla nova, bonita e bem feita de corpo. Nós tinha casado e estava vivendo no meu barraco na beira do rio... Vida de pobre, sabe como é, né? Não se vivia com riqueza, mas o de come nunca faltou... [...]. (MONTEIRO, 2000, p. 8).

\section{3.}

[...] Realmente ela veio. Ele estava escondido atrás de uma touceira de açaizeiros. Quando ela se aproximou, ele saiu e, com um revólver, atirou à queima-roupa em cima do peito da mulher, que caiu morta na praia.

Jorge e Júnior, ao darem falta do pai em casa, tinham saído atrás dele. E viram tudo. Quando a mulher caiu, os dois foram pra cima dela, chorando muito, abraçando e beijando o cadáver. [...]. (MONTEIRO, 2000, p. 17).

Nos exemplos acima, temos anáforas indiretas baseadas em relações semânticas inscritas nos SNs definidos e indefinidos. No caso de 1, a relação semântico-anafórica vai do SN definido para o indefinido, em que o elemento temático mais estrito aquela linda mulher recupera o elemento mais geral uma encantada destas, colocado antes na estrutura textual, configurando-se, aí, uma relação hipo/hiperonímica. Embora esta relação não seja tão fechada em termos de campos léxicos, ela passa a ter uma gradiência semântica em função do próprio modelo do mundo textual no qual a narrativa se insere, ou seja, aquele em que o referente aquela linda mulher pode fazer parte de um conjunto maior de seres encantados que povoam narrativas como as de Botos e Botas, tipo que está sendo aqui analisado.

De qualquer maneira, as características das narrativas e a forma como os elementos citados se estruturam na cadeia tópica, em nível de cotexto, levam a uma relação semântica de implicação, na qual o referente novo introduzido (aquela linda mulher) passa a compor o quadro ou cenário constituído por seres encantados, havendo também, nesse bojo, implicações de natureza contextual em nível de associação elemento x conjunto/universo.

No exemplo 2, é a expressão nominal indefinida uma cabocla nova que se refere à expressão definida a Mundica. Essa relação semântica é mais propriamente cotextual, isto é, dependente do quadro tópico em curso no processo narrativo contido na superfície do texto. No caso, é o elemento anafórico nominal indefinido uma cabocla nova que atua como uma hiponímia, já que especifica o referente 
anteriormente colocado na estrutura. Assim, a relação entre os sintagmas em análise se dá em função da estrutura tópica que está sendo "costurada", na qual se pode observar estratégias de reconstrução de referentes que vão do mais conhecido ou dado para o mais específico ou novo no transcurso da atividade referencial. Portanto, a própria cadeia de referência define as relações de contiguidade semântica a serem estabelecidas entre os elementos que estão sendo construídos na atividade verbal.

No que tange ao exemplo 3, a expressão o cadáver faz remissão direta ao sintagma a mulher, mas essa referência se implementa por meio de uma meronímia, em que o elemento o cadáver estabelece uma relação com o todo (o cadáver da mulher). Podemos dizer que esse tipo de anáfora opera também em nível estrutural ou sintagmático, pois parte do sintagma que se constitui como anaforizante retoma e reatualiza a totalidade do sintagma precedente, dando continuidade à relação referencial que está em andamento e, ao mesmo tempo, ensejando a inserção de novos eventos e objetos no processo de construção do texto.

Observem-se, a seguir, os excertos 4 e 5 e seus respectivos exemplos:

4.

[...] E o pajé continuou: - Pois é, ela estava menstruada. O Boto foi atraído por ela. Sabe como é, né? Sempre que mulher menstruada vai na beira do rio, o Boto vem pra atacar... os Botos perseguem a mulher menstruada. Mas como a mulher foi embora, o Boto resolveu te flechar...! [...]. (MONTEIRO, 2002, p. 24).

5 .

[...] Quando foram segurá-lo, não conseguiram. Apesar de ter só 10 anos, parecia ter uma força descomunal e tentava voltar para dentro d'água. Distribuía socos e ponta-pés e, liso como estava, se tornava muito difícil segurá-lo, tanto que cinco homens não conseguiram. Aí começaram a rezar, a rezar, a rezar e só com muita reza, com muitas orações é que conseguiram finalmente tirar Severino da beira do rio e levá-lo para casa. [...]. (MONTEIRO, 2000, p. 12).

Quanto ao excerto 4, observo a presença de uma AI baseada no papel temático do verbo, nesse caso, do verbo atacar. Nesse âmbito, evocando, aqui, as formulações teóricas de Tesnière (1977) acerca das valências verbais; e de Fillmore (1997), sobre a teoria dos casos e a teoria das funções-Teta do gerativismo, sugeridas por Marcuschi (2005), postulo que o verbo citado tem um papel temático ligado à ação ou processo, com o preenchimento de funções argumentais e semânticas do tipo: agente; \pm animado; humano ou não-humano (à esquerda) e objetivo; \pm animado; humano ou não-humano (à direita). Logo, a expressão nominal indefinida mulher menstruada cumpre o papel de preencher o significado instaurado pelo verbo e desencadeado pelo agente do processo aí embutido. Desse modo, em detrimento desse seu papel semântico/temático específico, o verbo atacar remete à expressão nominal precedente, cumprindo uma função anafórica exigida pelas relações de sentido próprias do co(n)texto em que está situado, estando ainda tal função 
coadunada com as características da narrativa aqui estudada e com os fatores culturais nos quais se inscreve.

Dando prosseguimento à análise dos recursos relativos à anáfora indireta, o excerto 5 referenda o uso de um tipo de AI baseada em elementos textuais ativados por nominalizações. Conforme observamos no trecho em questão, a expressão verbal começaram a rezar contém a forma repetida (infinitiva) a rezar, esta última ativada pela forma nominalizada muita reza e, em seguida, pela expressão sinonímica muitas orações, que reedita, com mais ênfase, o processo de nominalização posto em curso. Logo, como se vê, as formas nominalizadas instanciam uma força ilocutória bem maior do que as ações expressas pelos verbos (Cf. KOCH e MARCUSCHI, 1998), pois manifestam com mais propriedade e intensidade o caráter da atividade ilocucional. Nesse sentido, não são correferentes diretos dos verbos que ativam, mas expressões transmutadas desses verbos, carregando significações mais consistentes e relevantes que estes na cadeia referencial, quando desse processo de retomada.

Observemos, a seguir, os excertos 6, 7, 8, 9 e 10:

6.

[...] Severino não falava. E mudo ficou durante oito dias e oito noites, período em que não comeu nada e nem mesmo bebeu água...

Depois deste tempo, quando voltou a falar, contou para a mãe que, ao mergulhar, encontrou uma cobra encantada, que não sabia se era homem ou mulher. A cobra levou-o para uma cidade no fundo do rio, cidade esta que também era encantada. Em tudo parecia com as cidades da superfície, com uma só diferença: os seus habitantes eram todos cobras, cobras encantadas... [...]. (MONTEIRO, 2000, p. 12-13).

7.

[...] Ela fazia muitas maldades com as pessoas, malinava mesmo. Ano depois D. Belízia morreu. Dizem que deixou sua herança de Matinta para uma sobrinha... Eu não sei, porque logo depois eu me mudei... Mas dizem que a sobrinha continuou, pois nos anos que se seguiram, ouvia-se por aquelas redondezas ao chegar da noite:

- Firifififiuu... Firifififiu... (MONTEIRO, 2000, p. 19).

8.

[...] Teodoro Castro Barboza, 40 anos, filho de Sumaúma, lá em Igarapé-Miri, foi quem contou esta história. E ele continuou dizendo que a Matinta tanto perseguiu os moradores que um deles, mais corajoso, disse que ia dar um jeito naquela situação. Era o João Piraqueira, filho da Tia Podó, que era muito estimado naquelas bandas. [...]. (MONTEIRO, 2007, p. 15).

9.

[...] E, por mais incrível que pareça, D. Chiquinha, a Matinta Perera de Campo de Baixo, sobreviveu... Mas deixou uma lição: Lobisomem ou Matinta Perera 
não podem ver coisas sagradas nem ouvir nem pensar o nome de Deus, que o encanto se desfaz na hora! E foi o que aconteceu com D. Chiquinha: ela, como Matinta Perera, estava cumprindo a sua sina, porém, ao sobrevoar a ladainha de São Benedito, olhou para baixo, ouviu o nome de Deus, o encanto se desfez, e já em forma de gente, despencou lá de cima, caindo no tucumanzeiro... (MONTEIRO, 2000, 14).

10.

[...] Numa tarde, estávamos todos nós para um lado do roçado, e Ulisses, sozinho, estava trabalhando noutro local, um pouco distante. Eram cerca de seis horas da tarde quando ouvimos gritos de socorro. A voz não enganava: era de Ulisses. Corremos na direção dos gritos e ali encontramos Ulisses apavorado, sem conseguir sair de onde se encontrava. Mal conseguia falar. Quando pôde dizer alguma coisa, contou que estava trabalhando, quando sentiu como que uma presença perto de si. Ao olhar em torno, deu com aquele caboclinho bem perto. Espantou-se. Mais ainda porque não ouvira nenhum sinal de sua aproximação. Entretanto o caboclinho estava ali, a olhá-lo atentamente. Todo $n u$, o corpo moreno parecia feito de lascas de madeira marrom, como se fosse uma proteção...

Neste momento, Ulisses quis se mexer e não conseguiu. Sentiu-se estontear e pareceu ter perdido a noção do lugar, como se não soubesse onde estava... Foi quando começou a gritar. Ele não viu que direção tomou o caboclinho, só que quando chegamos não encontramos ninguém ali... Às 6 horas da tarde, no mato, fica tudo escuro como se fosse noite. Mas Ulisses afirmou que havia se encontrado com o Curupira. [...]. (MONTEIRO, 2000, p. 21).

O excerto 6, em exemplo, diz respeito a AI baseadas em esquemas cognitivos e modelos mentais. Esse tipo de anáfora está ancorado em construções conceituais ou em relações cognitivas atreladas a modelos mentais, que codificam experiências e conhecimentos de mundo armazenados em nossa memória de longo prazo. Assim, a expressão nominal definida este tempo, que também se estabelece como correferente da forma precedente indefinida período, ancora na sequência textual anterior a expressão oito dias e oito noites, dentre outras que poderiam ser ativadas, na nossa memória esquemática, relativas a tempo, como: dois meses, uma semana, cinco anos, quinze dias, etc. logo, este tipo de anáfora tem relação com esquemas culturais predefinidos, de forma que expressões como este tempo e período podem referir a um tempo delimitado, ao qual o narrador se reporta no decurso da história que está sendo contada. Desse modo, esses operadores temporais implicam uma espécie de restrição no que diz respeito ao sentido de tempo decorrido, o que já é, de certa maneira, pré-construído social e culturalmente. No entanto, não se tem, aí, uma relação de item para item em termos meramente lexicais, já que as formas período e este tempo não se ligam diretamente e conceitualmente à forma nominal que recuperam. Por outro lado, a relação entre os anaforizantes e a expressão nominal anaforizada se dá também em detrimento de constrições 
dadas pela própria natureza da atividade discursiva e dos sentidos pretendidos pelo produtor textual numa narrativa como a que está sendo contada.

Este mesmo tipo de anáfora ocorre no excerto 8, no qual a forma nominal naquelas bandas ancora as expressões toponímicas ou locativas Sumaúma e lá em Igarapé-Miri. Nesse sentido, a expressão dêitico-espacial naquelas bandas ativa um frame ou esquema cognitivo ligado à localidade, cidade, vila, lugarejo, povoado, município, etc. recuperável por meio de estruturas de conhecimento de mundo armazenadas e do modo de gerenciamento desses frames no nível da estruturação textual, no qual adquirem uma significação própria.

Acrescente-se, ainda, que a expressão anafórica naquelas bandas tem um papel rotulador ou encapsulador em relação às formas locativas que ancora, proporcionando uma espécie de dinâmica, de economia lexical e agilidade na condução do processo referencial.

Já nos exemplos 7, 9 e 10, temos AI baseadas em inferências ancoradas no modelo do mundo textual. Essas anáforas carregam informações disponibilizadas no modelo do mundo textual precedente e são fundadas em conhecimentos reconstruídos por meio de inferências realizadas a partir do conjunto de conhecimentos textuais postos em ação nas atividades de leitura/escrita. O resgate, aqui, desta pequena porção da teoria ajuda-nos a compreender melhor os exemplos retirados do corpus.

Assim, no excerto 7, a expressão definida a sobrinha continuou, cujo núcleo semântico é o verbo, ancora, do ponto de vista da própria natureza do texto apresentado e em sua relação com textos do mesmo perfil, a expressão (deixou) sua herança de Matinta. Portanto, é a partir de um tipo de configuração (con) textual específico que a expressão a sobrinha continuou faz sentido. Nesse caso, porque ancora uma entidade participante prototípica de certas formas narrativas amazônicas, nas quais o verbo continuar pode significar "herdar a sina de Matinta deixada por alguém", continuar fazendo as malinações típicas dessa personagem ou continuar com os seus assobios apavorantes, assustando as pessoas. De qualquer maneira, é na ligação com conhecimentos prévios acerca de um macromodelo de texto que as inferências supracitadas podem ser levantadas e que a forma verbal continuou é suscetível de ancorar a expressão colocada precedentemente na cadeia tópico-referencial.

É o que acontece de modo similar no excerto 9. A diferença reside no fato de que a ancoragem se dá de expressão nominal para expressão também nominal. Nesse caso, temos duas situações relativas a esse tipo de AI.

$\mathrm{Na}$ primeira, é a forma o encanto que ancora os referentes Lobisomem e Matinta Perera. Logo, restrições concernentes ao modelo textual em circulação numa dada sociedade levam à apreensão do significado veiculado por esse tipo de expressão, a qual, num outro modelo, operaria com significações outras, ancorando, obviamente, referentes de outro estatuto sociodiscursivo. Nesse sentido, as inferências realizadas na expressão o encanto são implementadas $a$ partir do contexto textual preexistente, ou seja, aquele em que tal expressão remete a significados pré-construídos relacionados a entidades como as afiliadas ao lendário aqui estudadas. O que é válido também para a segunda situação, na 
qual a forma (cumprindo) a sua sina possui um sentido de ancoragem conectado com a expressão Matinta Perera, que é reatualizada em função do tipo de configuração ligada ao modelo textual aí implementado. Portanto, em vista de significados recorrentes carreados por esse modelo, não se faz necessária uma explicitação do sentido implicado nessa expressão e da natureza semânticodiscursiva da ancoragem apresentada, pois a ligação estrita com o contexto em que são produzidas tais expressões leva à depreensão automática de significados ancoradores já estabilizados no âmbito da cultura de produção e circulação das histórias em pauta.

No exemplo 10, que considero ainda mais significativo do que o anterior, a expressão nominal inicial aquele caboclinho constitui a avaliação de um referente ainda não definido ou esclarecido no desenvolvimento tópico. Entretanto, no avançar deste, um conjunto de expressões descritivas nos faz apreender que se trata de um personagem chamado Curupira, trata-se das expressões: "todo nu, o corpo moreno parecia feito de lascas de madeira marrom, como se fosse uma proteção...", que compõem uma espécie de retrato do que se tem como uma construção mais ou menos típica e recorrente relativa a essa entidade, presente em histórias similares que são recontadas na Amazônia. Assim, uma espécie de modelo textual-cultural, contido também em outras narrativas, faz com que ativemos o frame Curupira, que, no contínuo referencial, é reativado pela anáfora indireta o caboclinho. Por conseguinte, somente após a colocação do conjunto descritivo - que "codifica"6 o personagem típico - o qual, por sua vez, se coaduna com o modelo do mundo textual precedente, é que temos a expressão definidora o Curupira, relevante para a construção do quadro tópico e para o modelo textual, que, de uma forma ou de outra, aí se apresenta em nível de materialidade. Assim, postulo acerca da relevância do conjunto descritivo supracitado, já que este tem o papel de remeter à construção sociocognitiva inerente ao personagem em questão, de modo a reconstruí-lo dentro do processo narrativo.

Considerando ainda o excerto em exemplo, é a partir do universo textual prévio que podemos entender o referente o caboclinho como ativando o frame o Curupira. Embora não determinante, esse tipo de referência pode se constituir como uma das formas por meio das quais se recategoriza esse personagem afiliado às construções lendárias.

Vejamos, abaixo, os excertos 11 e 12 e suas respectivas exemplificações:

11.

[...] - Olhe, eram mais ou menos das 6 pras 7 horas. Isto de hora respeitada não existe mais aqui. É bem difícil! Antigamente, sim. Meio-dia e meia-noite, 6 da manhã e 6 da tarde eram horas respeitadas até pra andar nas ruas. Mas isto era naquela época, que era tudo atrasado. Agora não. Agora o movimento

${ }^{6} \mathrm{O}$ termo "codifica", tomado em relação ao personagem típico o Curupira, indica, nesse co(n) texto, que tal personagem possui uma certa estabilidade sociodiscursiva quanto ao seu modo de se apresentar e/ou se configurar nas diversas narrativas contadas nas comunidades amazônicas. 
tá grande e já não aparecem estas coisas... Mas continuando a minha história. Então eu fui tomar banho no rio. Quando cheguei lá, tinha uma mulher se banhando. Com a minha chegada, ela saiu, foi embora, e eu fiquei. [...]. (MONTEIRO, 2002, p. 23-24).

12.

[...] Quando eu vim de lá, já cheguei em casa com muita febre e dor de cabeça. E que febre! Eu ardia todo...

Tinha um pajé aqui perto, o Izibinho - já até morreu -, e minha mãe mandou chamar ele.

Ele chegou, me examinou, fez as pajelanças dele com tauari e aquelas coisas que os pajés têm. Aí ele disse: - Quando tu chegaste lá, tinha uma mulher, não tinha?

Eu respondi: - Tinha... [...]. (MONTEIRO, 2002, p. 24).

Os excertos 11 e 12 referem-se às AI sem antecedente cotextual. Esse tipo de anáfora, segundo formulações dos autores acerca do assunto (Cf. Marcuschi, 2006), não consta da classificação das anáforas indiretas propriamente ditas, mas devido ao fato de não remeterem diretamente a um referente situado no próprio cotexto e, sim, a um referente do mundo extratextual, decidi incluí-lo na classificação aqui proposta.

Nos dois exemplos, as expressões estas coisas e aquelas coisas que os pajés têm constituem segmentos anafóricos não ancorados textualmente e sua interpretação não está na dependência da ativação de referentes já colocados anteriormente. Por conseguinte, é necessário que se recorra à memória discursiva, a conhecimentos de mundo e a conhecimentos partilhados para que seja possível interpretar elementos textuais dessa natureza. Proponho, então, que domínios de mundo biossocial possam ancorar os sentidos carreados por essas expressões, ou que estas, na perspectiva inversa constituam recursos que "amparam" o que já está significado ou dito nos citados domínios.

Por outro lado, pelo fato de tais expressões pertencerem a narrativas afiliadas ao universo do lendário amazônico, como as aqui analisadas e que, por sua vez, se enquadram em determinados domínios sociodiscursivos, é possível depreender os significados que concernem e para que referentes apontam dentro do citado universo. Essa depreensão depende de fatores sociocognitivos e de estratégias inferenciais, que passam a funcionar no momento da interação com essas formas e sentidos, a partir do que certos frames culturais são (re)ativados na memória de longo prazo, especificamente daqueles indivíduos que estão imersos no contexto ou no universo aqui focado.

Como as expressões em análise são mais ou menos típicas de certas atividades textual-discursivas, é possível remetê-las a certas narrativas, "alocandoas" em histórias semelhantes às aqui estudadas, nas quais determinados dizeres ou formas de dizer apontam/remetem para significados em circulação num dado contexto sociocultural, mas, nesse caso, sem uma ancoragem em nível de cotexto. Portanto, é a sua remissão extracotexto que faz com que possam os concebê-las 
como anáforas indiretas, ativando elementos do mundo sociocultural no qual as narrativas em questão são produzidas.

A categoria analisada evidenciou o fato de que as anáforas indiretas constituem recursos textuais importantes para a construção/elaboração de atividades discursivas ligadas aos personagens afiliados ao lendário e aos eventos relacionados a estes. A ativação de referentes prévios por meio desse tipo de anáfora mostra, de acordo com Marcuschi $(2006,2007)$, que as relações entre os objetos-de-discurso não são decorrentes de pontualizações estritas ou diretas, feitas pari passu, mas resultado de entrelaçamentos multidimensionais nas cadeias referenciais, que se apresentam como lacunosas, requerendo conhecimentos (com)partilhados, de âmbito comum, contextuais, para seu preenchimento e/ou compreensão.

Como extensão ao que propus acima, postulo que as construções anafóricas indiretas apresentam-se como elementos indiciadores de caráter meronímico, ancorados aos contextos nos quais as narrativas em foco são constituídas, estando aí implicadas estruturas de referência centradas em conhecimentos comuns/ coletivos de que se vale o produtor do texto no processo de elaboração das histórias estudadas. Por outro lado, esses elementos anafóricos de natureza indicial reativam, no contexto, estruturas de referência ${ }^{7}$ mais amplas ou mais extensas, mas que, por sua vez, também se colocam como insuficientes ou incompletas se não as entendermos como integradas aos seus contextos de produção cultural.

Em suma, se as relações entre os elementos cotextuais estão indissoluvelmente atreladas aos fatores contextuais, logo, isto se dá de maneira muito forte ou estrita no que se refere aos processos anafóricos indiretos, exigindo estratégias de inferência e interpretação mais acuradas quando da análise desses processos em textos orais e escritos, mais especificamente quanto às narrativas focalizadas neste trabalho.

A tabela abaixo mostra as ocorrências de Anáforas Indiretas presentes no corpus:

Tabela - Uso de anáforas indiretas.

\begin{tabular}{|c|c|c|c|c|c|}
\hline $\begin{array}{c}\text { Narrativas referentes aos } \\
\text { personagens lendários }\end{array}$ & Boto & Cobra & Matintaperera & Curupira & Total \\
\hline $\begin{array}{c}\text { Quantidade de narrativas } \\
\text { analisadas }\end{array}$ & 04 & 05 & 05 & 03 & 17 \\
\hline $\begin{array}{c}\text { Ocorrências de anáforas } \\
\text { indiretas }\end{array}$ & 51 & 61 & 34 & 14 & 160 \\
\hline Percentual (\%) & 31,88 & 38,12 & 21,25 & 8,75 & 100 \\
\hline
\end{tabular}

Fonte: Autor do artigo, a partir de dados apresentados na Revista Visagens, Assombrações e Encantamentos da Amazônia.

${ }^{7}$ Ao falar de estruturas de referência mais amplas ou mais extensas, pretendo dizer que estas, de certo modo, constringem ou demarcam sentidos (a serem) postos na cadeia referencial; no entanto, nem sempre é possível estabelecer uma relação direta entre o que está presente na superfície textual e elementos que compõem a estrutura de referência, a qual está atrelado um determinado texto. 
Segundo o que está expresso na tabela, detectei o somatório de 160 ocorrências de Anáforas Indiretas nos textos em análise, com uma média de 9,41 dessas anáforas por narrativa. Em se tratando de percentual, a maior incidência ocorreu em narrativas de Cobra, com um índice de 38,12\% de anáforas. Logo abaixo, apareceram as narrativas de Boto, com 31,88\% dessas formas, tendo-se, a seguir, as de Matintaperera, cuja incidência foi de $21,25 \%$. E, por fim, temos as de Curupira, que revelaram um índice de $8,75 \%$ de tais construções.

Os dados apresentaram, então, uma quantidade bastante significativa de construções anafóricas indiretas, o que reafirma o fato de que estas compõem o conjunto de elementos referenciais participantes da estrutura textual das histórias em estudo.

\section{CONSIDERAÇÕES FINAIS}

As narrativas de Cobra obtiveram um índice elevado de estratégias referenciais; nesse caso, no que diz respeito ao uso de anáforas indiretas, com um percentual de $38,12 \%$ desses elementos, o que mostra a importância do uso dessa estratégia para o processo de construção de tais narrativas. Assim, as implicações sociocognitivas contribuem para a veiculação desse tipo de anáfora, tendo em conta, em tal âmbito, as várias formas de construção da referência relacionadas ao personagem lendário em questão, nas quais estão também implicados tipos de significados variados e convergentes por meio dos quais esse personagem e eventos ligados a ele podem ser referidos tanto de forma direta como, sobretudo, de forma indireta. Observando a incidência total, detectei uma média 9,41\% dessas anáforas por narrativas, o que demonstra sua relevância no que concerne ao processo de construção de produções textuais como as que foram analisadas neste trabalho.

Com fundamento no que os dados apresentaram, as narrativas de Cobra foram as que mais revelaram o uso de anáforas indiretas, sendo seguidas pelas narrativas de Boto. É possível afirmar que isso ocorre em detrimento de um conhecimento sociocultural mais sedimentado e corrente acerca da construção desses personagens, já bastante disseminado no contexto no qual essas narrativas circulam, de modo que esse conhecimento cultural partilhado, acerca de tais entidades lendárias, leva ao uso de formas e expressões referenciais não estritamente ligadas às formas pontuais de referência de que são comumente portadoras, exigindo, por outro lado, processos de inferenciação, em cuja base estão esses conhecimentos coletivos partilhados, de caráter situativo.

Acrescente-se, nesse âmbito, que o conhecimento amplo e diversificado acerca da construção discursiva dos personagens Cobra e Boto, o qual envolve os fatores socioculturais supramencionados, deva propiciar o estabelecimento de processos referenciais indiretos relativos a tal construção. Logo, como os elementos dessa construção são também múltiplos e concomitantemente constringidos pelo contexto de onde emergem essas entidades lendárias, é possível que formas indiciárias partitivas e associativas levem automaticamente à sua remissão, 
assim como a eventos ou fatos que lhes são sociocognitivamente pertinentes, sem a necessidade de explicitude mais direta acerca destes, de modo que essas formas indiciais se constituem discursiva e pragmaticamente suficientes para $\mathrm{o}$ estabelecimento da ação referencial mobilizada pelo produtor do texto.

No caso das narrativas de Curupira, o percentual relativo ao uso de anáforas indiretas foi menos significativo do que nas narrativas referentes aos demais personagens lendários. É possível afirmar que isto se dê em razão do fato de que esse personagem se apresenta culturalmente como menos manipulado discursivamente, contendo, portanto, características mais ou menos fixas e estáveis no que diz respeito à sua construção. Logo, essa homogeneidade o leva a ser menos suscetível a processos anafóricos indiciais ou estabelecidos a partir de um conhecimento mais estrito, estando a sua figura já definida e tipificada no contexto cultural em que é construído e em que circula.

\section{REFERÊNCIAS BIBLIOGRÁFICAS}

APOTHÉLOZ, Denis; REICHLER-BÉGUELIN, Marie-José. Construction de la reference et strategies de désignation. In: BERRENDONNER, A; REICHLER-BÉGUELIN, M.-J. (eds). Du sintagme nominal aux objets-de-discours. Neuchâtel: Université de Neuchâtel, 1999, pp. 227-71.

FILLMORE, C. Lectures on Deixis. Stanford: CSLI Publications, 1997.

KOCH, I.G.V; MARCUSCHI, L.A. Processo de referenciação na produção discursiva. In: Delta, número especial, 1998, pp. 169-90.

KOCH, I.G.V. Referenciação: construção discursiva. Ensaio apresentado por ocasião do concurso para titular em Análise do Discurso do IEL/Unicamp, dez. 1999.

KOCH, I.G.V. Desvendando os segredos do texto. São Paulo: Cortez, 2002.

KOCH, I.G.V. Introdução à lingüistica textual: trajetória e grandes temas. São Paulo: Martins Fontes, 2004.

KOCH, I.G.V. Desvendando os segredos do texto. 5 ed. São Paulo: Cortez, 2006.

KOCH, I.G.V. As tramas do texto. Rio de Janeiro: Nova Fronteira, 2008.

MARCUSCHI, L.A. Anáfora indireta: o barco textual e suas âncoras. In: KOCH, I.G.V; MORATO, E. M; BENTES, A. C. (Orgs.). Referenciação e discurso. São Paulo: Contexto, 2005.

MARCUSCHI, L.A. Referenciação e cognição: o caso da anáfora sem antecedente. In: PRETI, D. (Orgs.). Fala e escrita em questão. São Paulo: Associação Editorial Humanitas, 2006.

MARCUSCHI, L.A. Cognição, linguagem e práticas interacionais. Rio de Janeiro: Lucerna, 2007.

MONTEIRO, W. Uma mulher muito Bonita. In: Visagens e Assombrações e Encantamentos da Amazônia. 2 ${ }^{\text {a }}$ ed. n. 3, Ano I. Belém: Smith - Produções Gráficas. 2000, p. 19-20.

MONTEIRO, W. História de beira de rio. In: Visagens e Assombrações e Encantamentos da Amazônia. $2^{\mathrm{a}}$ ed. n. 5, Ano II. Belém: Smith - Produções Gráficas. 2000, p. 8-10. 
MONTEIRO, W. Uma namorada e dois irmãos. In: Visagens e Assombrações e Encantamentos da Amazônia. $2^{\mathrm{a}}$ ed. n. 5, Ano II. Belém: Smith - Produções Gráficas. 2000, p. 15-18.

MONTEIRO, W. Malinação de boto. In: Visagens e Assombrações e Encantamentos da Amazônia. $2^{\mathrm{a}}$ ed. n. 7, Ano III. Belém: Smith - Produções Gráficas. 2002, p. 23-24.

MONTEIRO, W. O mergulho. In: Visagens e Assombrações e Encantamentos da Amazônia. $2^{\mathrm{a}}$ ed. n. 1, Ano I. Belém: Smith - Produções Gráficas. 2000, p. 12-13.

MONTEIRO, W. Uma história muito estranha. In: Visagens e Assombrações e Encantamentos da Amazônia. $2^{a}$ ed. n. 3, Ano I. Belém: Smith - Produções Gráficas. 2000, p. 10-13.

MONTEIRO, W. A velha Belizia. In: Visagens e Assombrações e Encantamentos da Amazônia. $3^{\mathrm{a}}$ ed. n. 2, Ano I. Belém: Smith - Produções Gráficas. 2000, p. 17-19.

MONTEIRO, W. A tia Podó. In: Visagens e Assombrações e Encantamentos da Amazônia. $2^{\text {a }}$ ed. n. 8 , Ano IV. Belém: Smith - Produções Gráficas. 2007, p. 15-18.

MONTEIRO, W. A ladainha de São Benedito. In: Visagens e Assombrações e Encantamentos da Amazônia. Belém. 2a ed. n. 5, Ano II. Belém: Smith - Produções Gráficas. 2000, p. 12-14.

MONTEIRO, W. Encontro com o curupira. In: Visagens e Assombrações e Encantamentos da Amazônia. $3^{a}$ ed. n. 2, Ano I. Belém: Smith - Produções Gráficas. 2000, p. 20-21.

MOURA, H. L. M. Atividades de referenciação em narrativas afiliadas ao universo do lendário da Amazônia: implicações sociocognitivas e culturais. 2013. Tese (Doutorado em Linguística. Área de Concentração: Linguística) - Instituto de Estudos da Linguagem, Universidade Estadual de Campinas, Campinas.

SCHWARZ, M. Indirekte Anaphern in Texten. Studien zur domangebundenen Referenz und Koharenz im Deutschen. Tubingen: Niemeyer, 2000.

TESNIÈRE, L. Élements de syntaxe structurale. Paris: Klincksieck, 1977.

Recebido: $24 / 02 / 2017$

Aceito: 07/04/2017 